\title{
Study of Short Stroke Control Model on Hot Rolling Mill
}

\author{
Lin Tan ${ }^{1}$, Lei Wang ${ }^{2}$, Xibang Zhang ${ }^{1}$ and Fengqin Wang ${ }^{1}$ \\ ${ }^{1}$ Shougang Research Institute of Technology, Beijing 100043, China \\ 2Shougang Qian'an Iron and Steel Company, Qian’an 064404, Hebei, China
}

\begin{abstract}
Head and tail width defects have a negative effect on hot strip quality. This paper developed a short stroke control (SSC) model to improve the width accuracy of head and tail. The model established a database to store the data of feature points, according to the steel grade and the working condition. This paper fitted the polynomial control curves with the feature points by the least square method, and executed the control curves on the vertical rolling. The results indicate that the model is useful for strip ends width control.
\end{abstract} square

Keywords—hot mill; vertical rolling; short stroke control; least

\section{INTRODUCTION}

Width is one of the important standards to evaluate the quality of hot rolling strip. Vertical rolling is the main method of width control. In the process of width reduction, head and tail width defects occur because of the different metal fluidity between the end and the body of strip. In order to prevent the problem, an on-line hydraulic press system is set up to change the opening of the vertical roll when the head and the tail pass the mill. This process is called short stroke control (SSC).

Many researchers have devoted much effort to analyze short stroke control model. Nikaido [1] built the width model of unsteady deformation in edge rolling by rigid-plastic finite element method. Li [2] built the FEA model for edging and horizontal rolling, which has been used to investigate the control model for head and tail shape on the roughing. Wu [3] established the slick curve model which has been applied to online controlling. Jiang [4] created the Causs Bell-shaped model to simulation analysis of short stroke control and the strip width control optimization.

In this work, the short stroke control model was studied based on the production control system in Qiangang $2250 \mathrm{~mm}$ hot strip rolling. The data of the feature points were designed and stored in the database, according to the steel grade and the working condition. The polynomial control curve was fitted with the feature points by the least square method. The method provides new ways to increase width accuracy.

\section{The PRINCIPLE OF SHORT Stroke CONTROL}

In the roughing mill, strips should be rolled alternately by vertical roller and horizontal roll, and the width of the strip can be controlled by the side pressure of the vertical roller. Because of the different metal fluidity between the end and the body of the strip, the longitudinal metal flow is more likely to occur on the two end of the strip [5]. This seriously affects the end sharp of the strip and the quality of width. Short stroke control is an advanced technology used to solve the end sharp defects. According to the contour curve of the head and tail, the vertical roll gap is changed continuously during the rolling process. If the roll gap variation curve is symmetrical and opposite to the contour curve, the width exception could be compensated. The control schematic is expressed in Figure I.

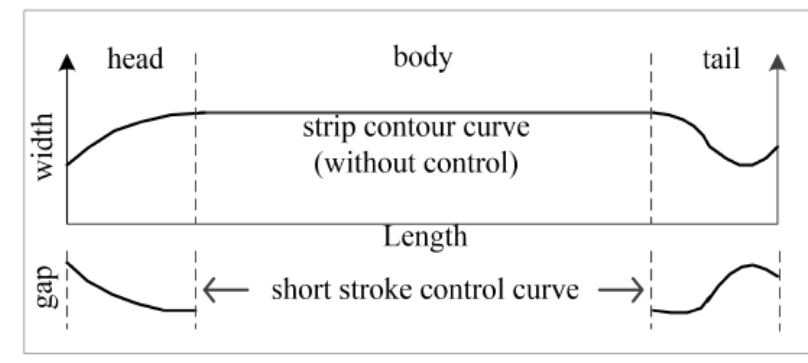

FIGURE I. SHORT STROKE CONTROL SCHEMATIC

In practical applications, the vertical roller short stroke control curve is usually made up of two parts. In the head control area, the gap opening of the terminal is the largest. As the rolling proceeds, the opening degree gradually shrinks to steady state(the opening of the strip body). In the tail control area, the strip contour curve is more complex, usually like the fishtail. The tail control curve is more complex than the head.

\section{The Polynomial Curve Model of Short Stroke CONTROL}

The core of the model is the control curve. This paper selects polynomial curve as the control curve. The polynomial curves have the following advantages: First, it smoother than broken line and more adaptable to the complex contour curve; Secondly, it is easy to adjust by the operator.

The data of the points which describe the characteristics of the curve was stored in a database. According to the steel grade and the working condition, the data could be queried when the strip is going to enter the rolling mill. The least square method is used to fit the control curve, with the data of the points. After the curve fitting, the polynomial equation is sent to the PLC for the strip head and tail sharp control. The flow chart of the control model is shown as Figure II. 


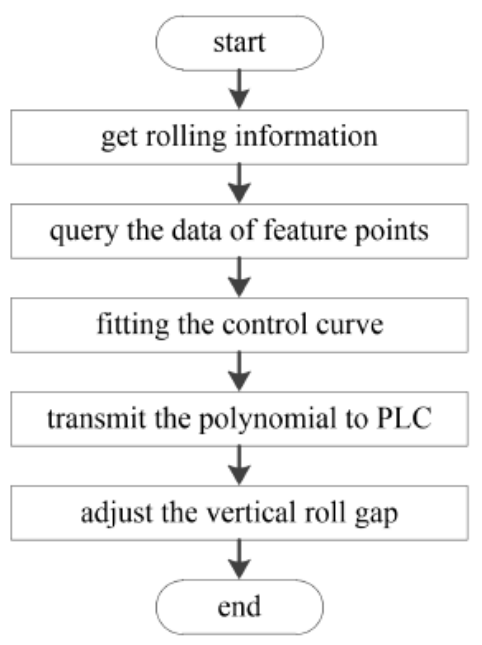

FIGURE II. FLOW CHART OF THE CONTROL MODEL

\section{A. The Database of the Feature Points}

The feature points data are the basis of the control curve. The database was built to store the feature points data. The basic functions of the database are the data storage and query. With different rolling conditions, the model uses different control curve. The feature points data should be classified according to rolling conditions. The rolling conditions associated with the defects of the strip include the yield strength, the entry width, the width reduction and the entry thickness. On the basis of yield strength, the strips are divided into 20 categories. The width of the main product is between $700 \mathrm{~mm}$ to $1800 \mathrm{~mm}$. The thickness of the main product is between $30 \mathrm{~mm}$ to $400 \mathrm{~mm}$ in rough rolling. The limit of the reduction of vertical roller is $60 \mathrm{~mm}$. The data classification rules are shown in Table I.

TABLE I. THE DATA CLASSIFICTION RULES OF DATABASE

\begin{tabular}{|c|c|c|}
\hline project & range & classification rules \\
\hline steel grade & $(0-20)$ & yield strength \\
\hline entry width & $\begin{array}{c}(700 \mathrm{~mm}- \\
1800 \mathrm{~mm})\end{array}$ & per $100 \mathrm{~mm}$ \\
\hline width reduction & $(0-60 \mathrm{~mm})$ & per $10 \mathrm{~mm}$ \\
\hline thickness & $(0-400 \mathrm{~mm})$ & per $100 \mathrm{~mm}$ \\
\hline
\end{tabular}

In accordance with the classification rules, the database has about 8000 groups of data, covering all rolling conditions. And the head data and the tail data are stored separately. Each group of data contains the coordinates of the 6 points, the length of the control area and the highest degree of the polynomial. The 6 feature points are used to describe the shape of the control curve. The point coordinate is shown as $P_{i}\left(x_{i}, y_{i}\right), x_{\mathrm{i}}$ represents the distance between the control start point and the point $P_{\mathrm{i}}$ in the direction of length. $y_{i}$ represents the distance between the strip body and the point $P_{i}$ in the direction of width. The length of the control area is usually less than $300 \mathrm{~mm}$.

\section{B. Least Square Fitting}

The least square method is a commonly used mathematical optimization technique. It searches for the best function matching of data by minimizing the sum of errors squares. The control curve was fitted with the feature points by the least square method. Based the feature points $P_{1}$ to $P_{6}$, the curve function was established as follows:

$$
p(x)=a_{0}+a_{1} x+\ldots+a_{m} x^{m} \quad(2<\mathrm{m}<5)
$$

The optimal conditions can be expressed as follows:

$$
\sum_{i=1}^{n}\left(p\left(x_{i}\right)-y_{i}\right)^{2}=\mathrm{MIN}
$$

Replace $p(x)$ in (2) with (1):

$Q\left(a_{0}, a_{1}, \ldots, a_{m}\right)=\sum_{i=1}^{n}\left(a_{0}+a_{1} x+\ldots+a_{m} x^{m}-y_{i}\right)^{2}=\mathrm{MIN}$

Solve the above equation, transform (3) as follows:

$$
\left\{\begin{array}{l}
n a_{0}+\left(\sum_{i=1}^{n} x_{i}\right) a_{1}+\ldots+\left(\sum_{i=1}^{n} x_{i}^{m}\right) a_{m}=\sum_{i=1}^{n} y_{i} \\
\left(\sum_{i=1}^{n} x_{i}\right) a_{0}+\left(\sum_{i=1}^{n} x_{i}^{2}\right) a_{1}+\ldots+\left(\sum_{i=1}^{n} x_{i}^{m+1}\right) a_{m}=\sum_{i=1}^{n} x_{i} y_{i} \\
\ldots \\
\left(\sum_{i=1}^{n} x_{i}^{m}\right) a_{0}+\left(\sum_{i=1}^{n} x_{i}^{m+1}\right) a_{1}+\ldots+\left(\sum_{i=1}^{n} x_{i}^{2 m}\right) a_{m}=\sum_{i=1}^{n} x_{i}^{m} y_{i}
\end{array}\right.
$$

The solution $\left(a_{0}-a_{\mathrm{m}}\right)$ of the (4) is the coefficient of the control curve. After the fitting of the control curve, the coefficient of the control curve will be sent to the PLC. When the strip pass passes through the vertical roll, The opening of the head and tail will change with the curve.

\section{ApPlication OF THE SHORT Stroke CONTROL}

The polynomial curve model and the database have been established on the production control system in Qiangang 2250 mm hot strip rolling. Tail short stroke experiments have been conducted to verify the accuracy of the model. Every experimental strip rolling five times in the rough mill. Only in the forward pass, vertical roller is enabled. The basis rolling information is shown in Table II.

TABLE II. ROLLING INFORMATION OF FORWARD PASSES

\begin{tabular}{|c|c|c|c|c|c|}
\hline \multirow{2}{*}{ pass } & \multirow{2}{*}{$\begin{array}{c}\text { steel } \\
\text { grade }\end{array}$} & \multicolumn{2}{|c|}{ width(mm) } & \multicolumn{2}{c|}{ thickness(mm) } \\
\cline { 3 - 6 } & & entry & reduction & entry & reduction \\
\hline 1 & M3A33 & 1155 & 30 & 220 & 40 \\
\hline 3 & M3A33 & 1167 & 24 & 156 & 37 \\
\hline 5 & M3A33 & 1171 & 9 & 87 & 24 \\
\hline
\end{tabular}

According to the rolling information, the data of the feature points are queried from the database. In the pass 1 , the curve function is quadratic equation, and the length of the control area is $1.0 \mathrm{~m}$; In the pass 3 , the curve function is cubic equation, and the length of the control area is $1.2 \mathrm{~m}$; In the pass 5 , the 
curve function is quintic equation, and the length of the control area is $1.6 \mathrm{~m}$. The data of the feature points coordinates is shown in Table III.

TABLE III. THE DATA OF TAIL FEATURE POINTS

\begin{tabular}{|c|c|c|c|c|c|c|}
\hline \multirow{2}{*}{ pass } & \multicolumn{6}{|c|}{ the feature points coordinates(mm) } \\
\cline { 2 - 7 } & $\mathbf{P 1}$ & $\boldsymbol{P 2}$ & $\boldsymbol{P 3}$ & $\boldsymbol{P 4}$ & $\boldsymbol{P 5}$ & $\boldsymbol{P 6}$ \\
\hline \multirow{2}{*}{1} & $\begin{array}{c}(0,1 \\
)\end{array}$ & $(0.2,1)$ & $(0.4,3)$ & $(0.6,2)$ & $(0.8,1)$ & $(1,0)$ \\
\hline 3 & $\begin{array}{c}(0,2 \\
)\end{array}$ & $\begin{array}{c}(0.48, \\
3)\end{array}$ & $\begin{array}{c}(0.72,1 . \\
5)\end{array}$ & $\begin{array}{c}(0.96,0 . \\
5)\end{array}$ & $\begin{array}{c}(1.08,- \\
1)\end{array}$ & $\begin{array}{c}(1.2,0 \\
)\end{array}$ \\
\hline 5 & $\begin{array}{c}(0,3 \\
)\end{array}$ & $\begin{array}{c}(0.64, \\
4)\end{array}$ & $(0.96,2)$ & $(1.28,-2)$ & $\begin{array}{c}(1.44,- \\
3)\end{array}$ & $\begin{array}{c}(1.6,- \\
1)\end{array}$ \\
\hline
\end{tabular}

The tail control curve of the three passes was fitted by the least square method, with the date of the feature points coordinates. The tail control curves are shown in Figure III. The opening of the vertical roll was adjusted on the basis of the tail control curves.

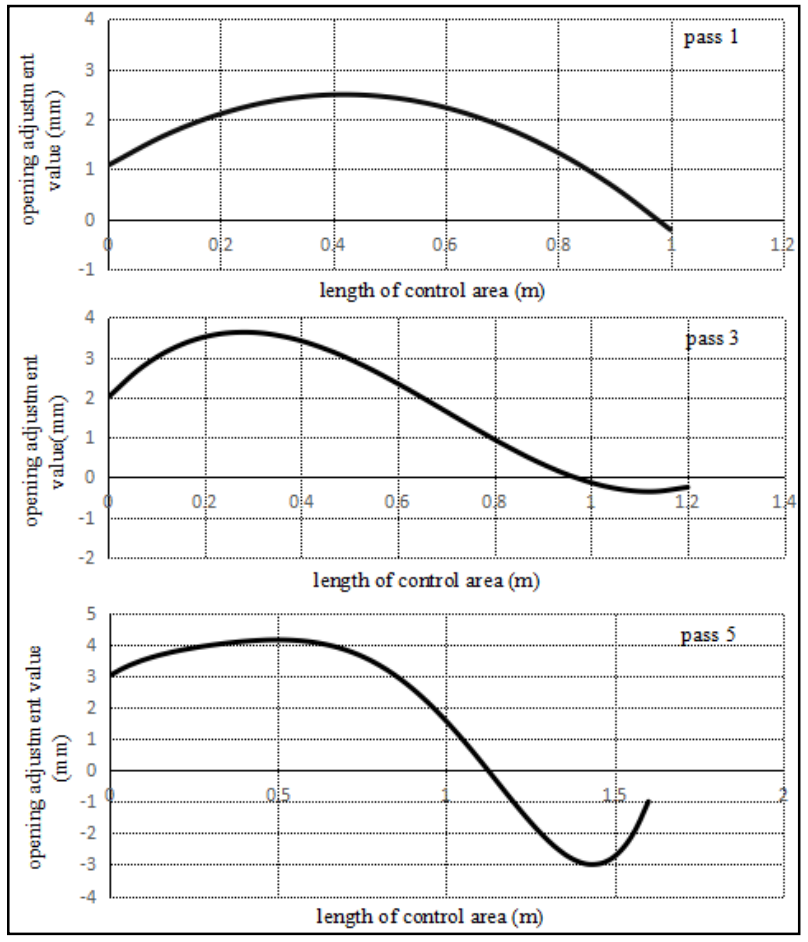

FIGURE III. THE TAIL CONTROL CURVES

A comparable experiment was conducted to test the validity of the control model. Two strips produced in the same batch, which had the same steel grade and the same dimensions as above mentioned. The former one used the short stroke control, the latter did not use the short stroke control. Tail width measurement results are shown in Figure IV. The results show that short stroke control not only reduces the deviation, but also shortens the length of the tail defect area.

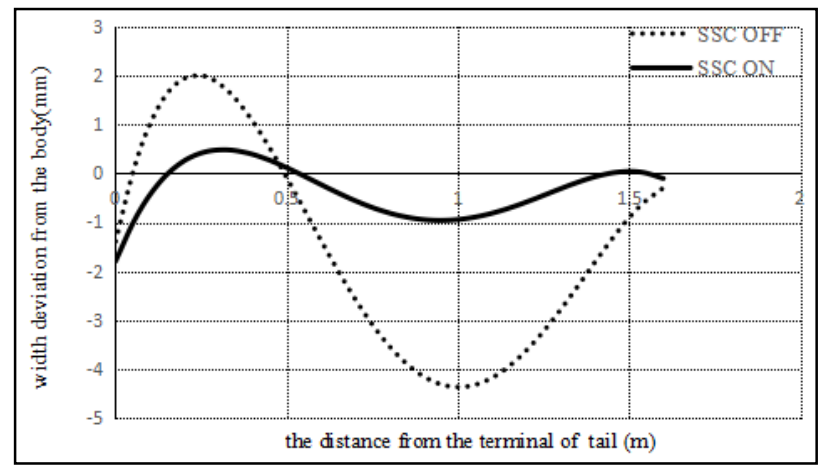

FIGURE IV. TAIL WIDTH MEASUREMENT RESULTS

The short stroked control model has been used in the Qiangang 2250mm hot strip rolling for all kinds of strips. The width accuracy is increased from $98.15 \%$ to $98.50 \%$, and the disqualification caused by the width defects of head and tail reduced by $70 \%$.

\section{CONCLUSIONS}

The strip head and tail defects can be resolved by the short stroke control model. The model was established on the polynomial control curve, which was fitted with the feature points by the least square method. The experiments show that the new model not only reduces the deviation, but also shortens the length of the tail defect area. The application of the model improves the precision of width control and reduced disqualification caused by the width defects of strip head and tail.

\section{REFERENCES}

[1] Nikaido H, Naoi T, Shibata K, "FEM Simulation of Nonsteady Deformation in Edge Rolling [J]”. Japanese Soc Tech Plasticity, 1983, 24(268):486-492.

[2] Li Xuetong, Huang Zhaomeng, Wang Minting, "Research on SSC curve on roughing mill using FEM and optimization [J]". Chinese Journal of Computational Mechanics, 2012, 29(4):61.

[3] Wu Jianfeng, Wang Guodong, "Study and practice of optimizing short stroke control of strip hot rolling [J]”. Iron and Steel, 2008, 43(8):44.

[4] Jiang Xiao, Nan Ning, Yu Wei, "Study of short stroke control model of Qiangang 2160 hot strip mill [J]”. Iron and Steel, 2009, 44(8):64.

[5] Xiong Shangwu, Lv Cheng, Liu Xianghua, "Simulation of Unsteady State Edging Process by Full Three Dimensional Rigid Plastic Finite Element Method [J]”. Journal of Northeastern University, 1999, 20(6):647-650 